\title{
Characterization of black slags obtained during smelting in the electric arc furnace from SIDERPERU following reduction
}

\author{
H. A. Cabrera-Tinoco ${ }^{1,2} \cdot$ R. A. Valencia-Bedregal ${ }^{1} \cdot$ L. E. Borja-Castro ${ }^{1}$. \\ M. I. Valerio-Cuadros ${ }^{1,3} \cdot$ A. G. Bustamante Dominguez ${ }^{1} \cdot$ Xiaoli Zhao $^{4}$. \\ Youyun Zhang ${ }^{4}$. Chengmu Zheng ${ }^{4} \cdot$ N. O. Moreno ${ }^{5}$. Deliang Zhang ${ }^{4}$. \\ C. H. W. Barnes ${ }^{6} \cdot$ L. De Los Santos Valladares ${ }^{1,4,6} \mathbb{D}$
}

Accepted: 2 January 2022 / Published online: 17 January 2022

(c) The Author(s) 2022

\begin{abstract}
The primary process in an electrical arc furnace (EAF) during industrial steelmaking results in tons of black slags which cause pollution to the environment. In this work, the iron oxides of black slags generated in the EAF from the SIDERPERU plant, Peru was reduced via the carbothermal reaction. The reduction of the black slag to $\alpha$-Fe is demonstrated by X-ray diffraction, Mössbauer spectroscopy and magnetometry. However, phases with calcium and silicon persist in the sample after the carbothermal process. The thermodynamic calculations of the most probable reactions sequence were performed to understand the reduction process. The magnetometry measurements confirm the presence of ferromagnetic domains, supporting the success of the reduction of the black slag to $\alpha$-Fe. The reduced black slags were recycled into a HRB335 steel rod by consolidation and extrusion processes and inspected by X-ray fluorescence.
\end{abstract}

Keywords Black slag · iron oxides · electric arc furnace · carbothermal reduction · Mössbauer spectroscopy, HRB335 steel

\section{Introduction}

Steel production is one of the most important economic activities for industrial development worldwide [1, 2]. However, the industry faces great challenges mainly related to the environmental impact caused by pollution due to millions of tons of slags generated every year [3-5]. One of the ways to reduce pollution is the recycling of scrap from an electric

This article is part of the Topical Collection on Proceedings of the International Conference on the Applications of the Mössbauer Effect (ICAME 2021), 5-10 September 2021, Brasov, Romania Edited by Victor Kuncser

H. A. Cabrera-Tinoco

hadriel.rdsd@gmail.com

L. De Los Santos Valladares

1d301@cam.ac.uk

Extended author information available on the last page of the article 
arc furnace (EAF) into new steel which is known as 'Secondary production'. The use of steel scrap implies a great reduction in energy consumption and $\mathrm{CO}_{2}$ emissions. However, the first steelmaking process in an EAF also generates black slags rich in iron oxides, such as hematite $\left(\alpha-\mathrm{Fe}_{2} \mathrm{O}_{3}\right)$, magnetite $\left(\mathrm{Fe}_{3} \mathrm{O}_{4}\right)$ and wüstite $(\mathrm{FeO})$ [6]. It is not possible to directly recycle black slags into new steel ingots since the containing oxides would make the resulting pieces brittle. In order to recycle black slags, the reduction of iron oxides is prior needed. Thus, the metal iron could be used as a raw material for steel production.

Although the reduction of iron oxides has been widely investigated, there is not much information about the reduction of the black slags as such. Even more, there is still a lack of comprehension about the chemical mechanisms governing the reduction processes of the iron oxide components [7]. Nevertheless, some progress is reported in the literature. For example, the reduction process of hematite in a blast furnace is well known [8]. During this process, iron-bearings (pellet, sinter, and lump) and coke are placed inside the blast furnace at high temperatures and after a sequence of solid and gaseous reactions, the iron is obtained, which is separated from the other materials by density [9]. Furthermore, recently the recovery of pure iron through carbothermal reduction of discarded iron ore slimes produced in the mining extraction of iron was reported [10]. And this technique was also used to reduce copper slag from the pyrometallurgical treatment of metalliferous minerals and obtained iron [11]. Besides, the iron ore reduction process is quite complex and can be carried out through various reaction paths depending on the thermodynamic conditions of the process [12].

In this work, we report the reduction of black slag produced after scrap smelting in the EAF from the SIDERPERU steel plant, Chimbote city, Perú. The sample was carbothermal reduced and characterized using X-Ray diffraction (XRD) and Mössbauer spectroscopy (MS). The XRD identified the mineralogical composition, whereas the use of MS was fundamental to identify the iron oxides in the sample. Thermodynamic calculations were used to clarify the reactions occurring during the reduction process and magnetometry measurements were performed to analyse the magnetic properties of the sample. The reduced black slags were recycled into HRB335 steel by consolidation and extrusion and analysed by X-ray fluorescence (XRF).

\section{Experimental}

The sample analysed in this article was collected from the first smelting process in the EAF belonging to the company SIDERPERU located in Chimbote city, Peru. In the EAF, the waste can be separated from the liquid steel due to differences in densities. The waste was collected from this remnant material, and it is named black slags because of its characteristic colour. After being collected, the samples went through a crushing process until the grain size ranged in the interval $53-600 \mu \mathrm{m}$ and were sieved in a $72 \mu \mathrm{m}$ mesh. The X-ray diffraction measurements were performed in a Shimadzu brand diffractometer (model XRD-6000) using cobalt (Co $\left.K_{\alpha}\right)$ radiation. The $2 \theta$ data collection ranged from $20^{\circ}$ to $80^{\circ}$ with a step of $0.02^{\circ}$ and a velocity of $4 \mathrm{~s} /$ step.

The reduction process was carried out through a carbothermal reaction in a tubular furnace in an argon atmosphere. Previously, the sample was mixed with graphite in the ratio sample: graphite 5:1. The thermal treatment was performed in three steps. First, the sample was heated at $10^{\circ} \mathrm{C} /$ min until reaching a temperature of $1000^{\circ} \mathrm{C}$, keeping it at this temperature for one hour, then the temperature was increased to $1150^{\circ} \mathrm{C}$ for one hour and finally, the temperature was increased up to $1200^{\circ} \mathrm{C}$ for $2 \mathrm{~h}$. 
The Mössbauer spectroscopy was performed using a 57Co (Rh) radioactive source of $50 \mathrm{mCi}$ of nominal activity, linear velocity and at room temperature (RT). The spectrometer was calibrated at room temperature using $\alpha$-Fe as an absorber and was adjusted using the WinNormos program applying Lorentzian functions. The magnetic measurements of the sample were performed in a DC-MPMS-SQUID magnetometer from Quantum Desing Inc. The magnetization response with temperature $\mathrm{M}(\mathrm{T})$ was collected in zero-field cooling (ZFC) and field cooling (FC) modes under 500 Oe and $5 \mathrm{kOe}$. The magnetization response with the applied field was collected in the range $\pm 10 \mathrm{kOe}$ at 10 and $300 \mathrm{~K}$.

The reduced black slags were recycled into a HRB335 steel rod by following consolidation and extrusion at $400{ }^{\circ} \mathrm{C}$. The rod was filled by a Wire Electrical Discharge Machine (WEDM) and the chips were inspected through an optical Olympus CX23 microscope at $40 \times$. The XRF analysis for elemental composition was performed in EDX-720 Shimadzu equipment.

\section{Results and discussions}

Figures 1(a) and (b), respectively, show the XRD of the sample before and after the reduction process. The black slag sample (Fig. 1(a)) presents calcium silicon (CaSi, ICSD card No. 01-074-0147), magnetite ( $\mathrm{Fe}_{3} \mathrm{O}_{4}$, ICSD card No. 01-076-1849), srebrodolskite $\left(\mathrm{Ca}_{2} \mathrm{Fe}_{2} \mathrm{O}_{5}\right.$, ICSD card No. 00-047-1744), larnite $\left(\mathrm{Ca}_{2} \mathrm{SiO}_{4}, \mathrm{ICSD}\right.$ card No. 00-033-0303),

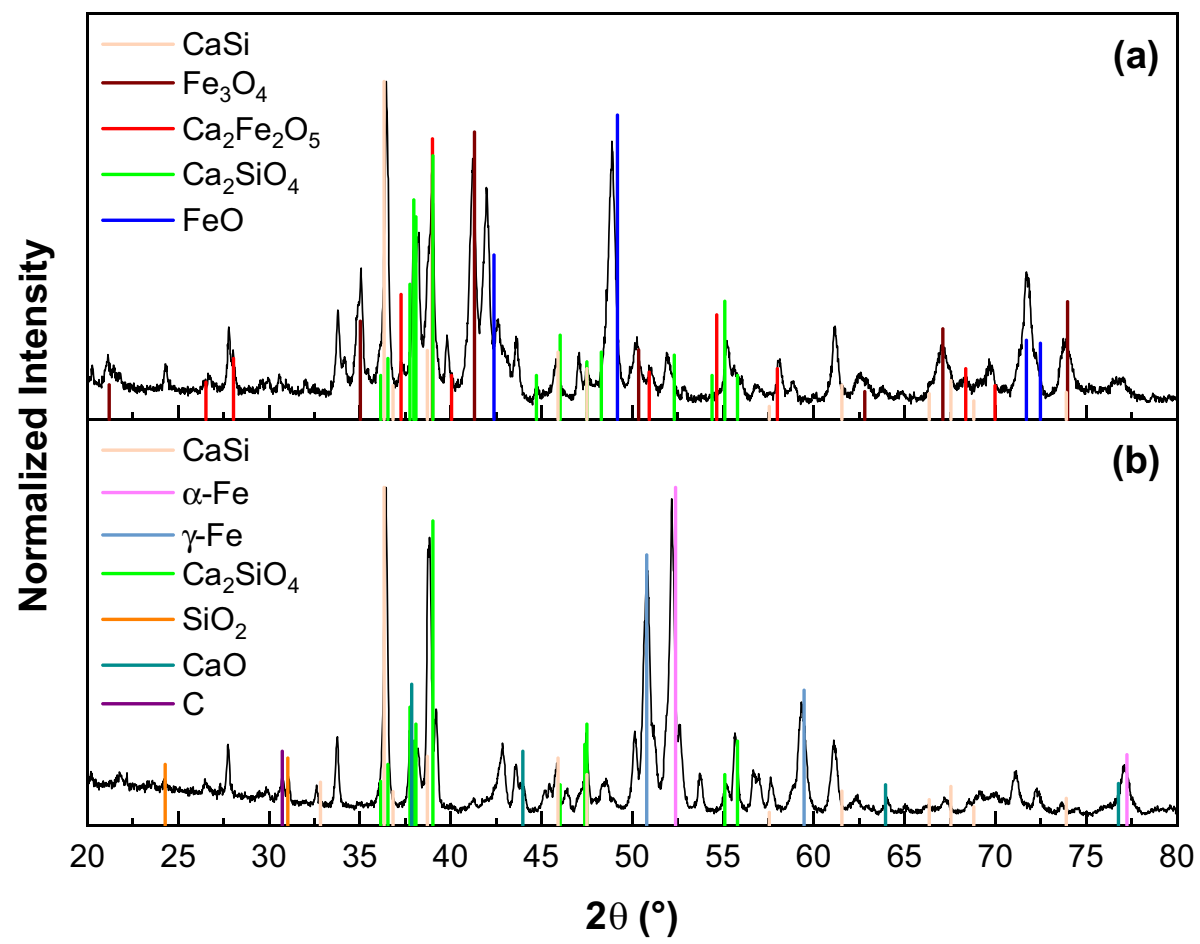

Fig. 1 XRD obtained by Co-radiation of a black slag collected from the electrical arc furnace from SIDERPERU: a) Before and b) after carbothermal reduction process 
Fig. 2 Mössbauer spectra of the black slags from the electric arc furnace (EAF) before (a) and after (b) carbothermal reduction process and the corresponding hyperfine field distribution $\mathrm{P}\left(\mathrm{B}_{\mathrm{hf}}\right)$ fitted with four Gaussian functions (left axis), and linear correlation between $\mathrm{B}_{\mathrm{hf}}$ and the isomer shift (right axis) (c)

and wüstite (FeO, ICSD card No.01-073-2143). These components are in good agreement with the composition of EAF slags reported in the surveys performed by Teo et al. and Menad et al. [13, 14]. Fig. 1(b) shows the XRD of the black slag sample after carbothermal reduction. The reduction is demonstrated by the lack of iron oxides components and the presence of ferrite ( $\alpha$-Fe, ICSD card No. 01-087-0721) and austenite ( $\gamma$-Fe, ICSD card No.01-901-4056). The calcium silicon remains after the reduction process. Besides, other phases such as $\mathrm{CaO}$ (ICSD card No. 01-074-1226) and $\mathrm{SiO}_{2}$ (ICSD card No. 01-085-0335) might come from the partial decomposition of $\mathrm{Ca}_{2} \mathrm{SiO}_{4}$. It means that the conditions were enough to reduce the iron oxide contents, but it was not sufficient to completely decompose $\mathrm{Ca}_{2} \mathrm{SiO}_{4}$, persisting in the XRD. A little amount of unreacted carbon (C, ICSD card No. 00-041-1487) is also detected in the XRD suggesting that lower amounts of C could be also used to achieve the reduction of the iron oxide components. Note that there are some other peaks not identified in the diffractogram coming from impurity phases in the sample.

Figures 2(a) and (b) show the Mössbauer spectra of the black slags before and after the carbothermal reduction process, respectively. The hyperfine parameters and relative areas are listed in Table 1. The spectra fitting for the black slag sample before reduction (Fig. 2(a)) shows two doublets corresponding to nonstoichiometric wüstite $\left(\mathrm{Fe}_{1-\mathrm{x}} \mathrm{O}\right)$. The electronic exchange between $\mathrm{Fe}^{2+}$ and $\mathrm{Fe}^{3+}$ in octahedral sites is presented as one doublet with $\mathrm{IS}=1.01 \mathrm{~mm} / \mathrm{s}$ and $\mathrm{QS}=0.97 \mathrm{~mm} / \mathrm{s}$. The other doublet, with $\mathrm{IS}=0.35 \mathrm{~mm} / \mathrm{s}$ and $\mathrm{QS}=0.72 \mathrm{~mm} / \mathrm{s}$, is attributed to the electronic exchange between tetrahedral $\mathrm{Fe}^{3+}$ and octahedral $\mathrm{Fe}^{2+}$ sites in wüstite $[15,16]$. In addition, two sextets of hyperfine fields $\mathrm{B}_{\mathrm{hf}}=48.8$ and $45.7 \mathrm{~T}$, typical for magnetite are observed for tetrahedral $\mathrm{Fe}^{3+}$ and octahedral $\mathrm{Fe}^{2+} /$ $\mathrm{Fe}^{3+}$ sites $[17,18]$. The ratio of the area between octahedral and tetrahedral sites is around 1.8 and this value is related to the lower Mössbauer fraction in $\mathrm{Fe}^{2+} / \mathrm{Fe}^{3+}$ (Site B) than in $\mathrm{Fe}^{3+}$ (Site A) [19]. The last two sextets correspond to $\mathrm{Ca}_{2} \mathrm{Fe}_{2} \mathrm{O}_{5}$ with octahedral and tetrahedral $\mathrm{Fe}^{3+}$ sites with $\mathrm{B}_{\mathrm{hf}}=50.6$ a $41.9 \mathrm{~T}[20,21]$.

After the carbothermal reduction process, the fitting of the spectrum (see Fig. 2(b)) shows one paramagnetic singlet with IS $=-0.12 \mathrm{~mm} / \mathrm{s}$ related to austenite $(\gamma-\mathrm{Fe})[22,23]$, and one paramagnetic doublet with $\mathrm{IS}=0.17 \mathrm{~mm} / \mathrm{s}$ and $\mathrm{QS}=0.41 \mathrm{~mm} / \mathrm{s}$ associated to $\mathrm{Fe}^{3+}$ in a tetrahedral site. The plot shown in Fig. 2(c) provides the hyperfine magnetic field distribution $\mathrm{P}\left(\mathrm{B}_{\mathrm{hf}}\right)$ using 40 magnetic sub-spectra with the linear correlation between $\mathrm{B}_{\mathrm{hf}}$ and isomer shift. Four peaks (G01-G04) corresponding to 33.5, 31.0, 29.3 and $26.0 \mathrm{~T}$ were calculated using four Gaussian functions. The value of the highest peak $(33.5 \mathrm{~T})$ is very close to that for ferrite $[24,25]$. The other peaks could be related to the superparamagnetic relaxation due to the presence of nanoparticles, with large distribution size, formed during the carbothermal reduction process at high temperatures [26]. Note that the presence of ferrite and austenite here is in well agreement with the XRD analysis above and confirms the reduction of the black slags.

Figure 3 shows the magnetic measurements of the reduced sample. Fig.3(a) shows the temperature dependence of the magnetization $M(T)$ obtained under 500 Oe and 5 kOe applied fields. Note that the magnetization values decrease when the temperature increases indicating a strong paramagnetic alignment which might be generated by $\mathrm{CaSi}, \mathrm{C}, \mathrm{Ca}_{2} \mathrm{SiO}_{4}, \mathrm{CaO}, \mathrm{SiO}_{2}$ and other impurities. However, the presence of a ferromagnetic contribution (assumed to come from the $\alpha-\mathrm{Fe}$, detected by the other techniques 

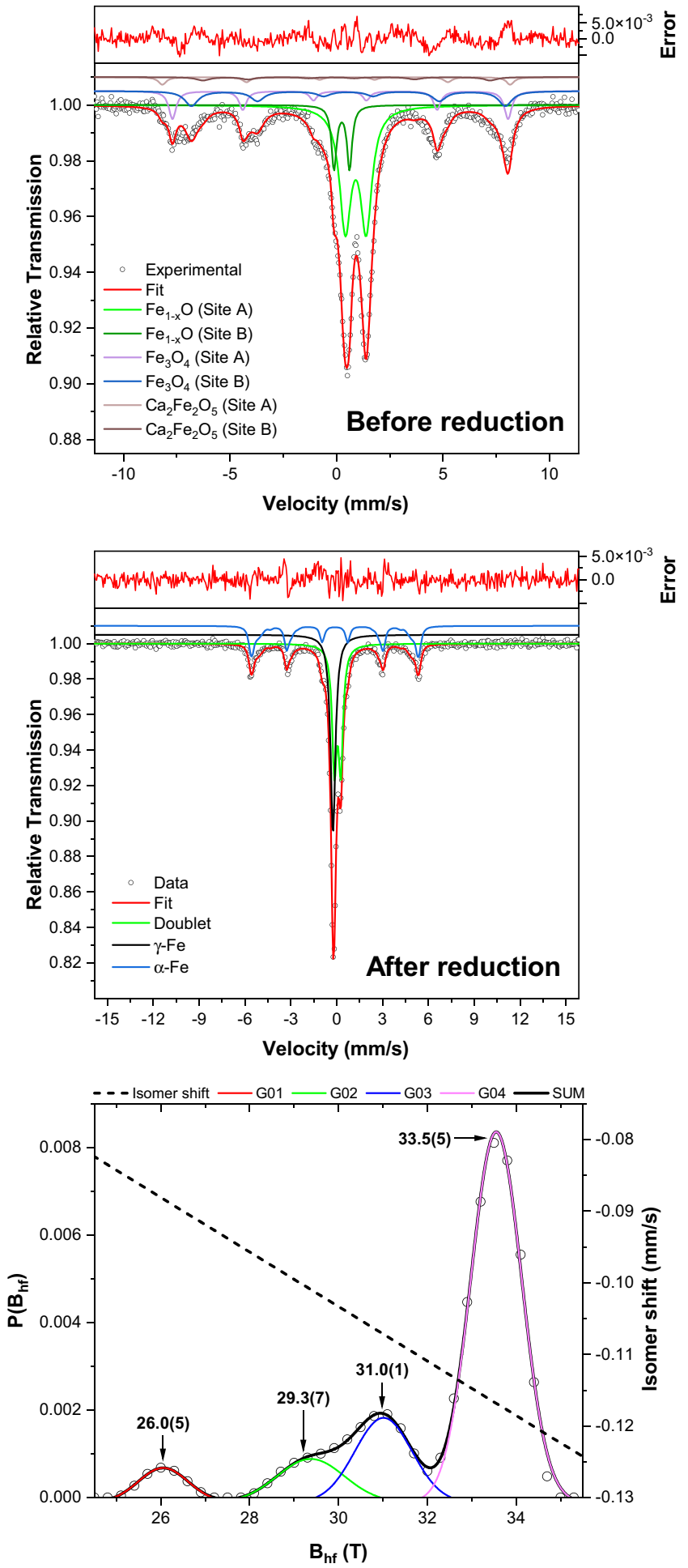
Table 1 Mössbauer parameters of the black slag samples before and after the carbothermal reduction process.

\begin{tabular}{|c|c|c|c|c|c|c|}
\hline Site & & IS $(\mathrm{mm} / \mathrm{s})$ & $\mathrm{QS}(\mathrm{mm} / \mathrm{s})$ & $\mathrm{B}_{\mathrm{hf}}(\mathrm{T})$ & $\mathrm{W}(\mathrm{mm} / \mathrm{s})$ & $\mathrm{RAA}^{*}(\%)$ \\
\hline \multicolumn{7}{|c|}{ Before carbothermal reduction } \\
\hline \multirow[t]{2}{*}{$\mathrm{Fe}_{1-\mathrm{x}} \mathrm{O}$} & $\mathrm{Fe}^{2+}$ & $1.01(1)$ & $0.97(9)$ & - & $0.66(3)$ & $57.2(2)$ \\
\hline & $\mathrm{Fe}^{3+}$ & $0.35(6)$ & $0.72(8)$ & - & $0.29(2)$ & $5.8(5)$ \\
\hline \multirow[t]{2}{*}{$\mathrm{Fe}_{3} \mathrm{O}_{4}$} & $\mathrm{Fe}^{3+}$ & $0.27(6)$ & $0.01(6)$ & $48.8(8)$ & $0.41(6)$ & $10.5(7)$ \\
\hline & $\mathrm{Fe}^{2+} / \mathrm{Fe}^{3+}$ & $0.66(5)$ & - & $45.7(3)$ & $0.76(6)$ & 19.1(7) \\
\hline \multirow[t]{2}{*}{$\mathrm{Ca}_{2} \mathrm{Fe}_{2} \mathrm{O}_{5}$} & $\mathrm{Fe}^{3+}$ & $0.35(2)$ & $-0.51(1)$ & $50.6(7)$ & $0.44(7)$ & $3.3(8)$ \\
\hline & $\mathrm{Fe}^{3+}$ & $0.22(1)$ & $0.71(2)$ & $41.9(1)$ & $0.74(7)$ & $4.1(1)$ \\
\hline \multicolumn{7}{|c|}{ After carbothermal reduction } \\
\hline$\gamma-\mathrm{Fe}$ & $\mathrm{Fe}^{0}$ & $-0.12(5)$ & - & - & $0.38(5)$ & $34.1(8)$ \\
\hline Doublet & $\mathrm{Fe}^{3+}$ & $0.17(8)$ & $0.41(6)$ & - & $0.35(7)$ & $37.7(1)$ \\
\hline Distribution & & $<\mathrm{IS}>(\mathrm{mm} / \mathrm{s})$ & $2 \varepsilon(\mathrm{mm} / \mathrm{s})$ & $<\mathbf{B}_{\mathrm{hf}}>(\mathbf{T})$ & $\mathbf{W}(\mathbf{m m} / \mathbf{s})$ & $\mathbf{R A A} *(\%)$ \\
\hline$\alpha-\mathrm{Fe}$ & $\mathrm{Fe}^{0}$ & $0.00(5)$ & - & $32.6(6)$ & $0.30(0)$ & $28.2(1)$ \\
\hline
\end{tabular}

*RAA: Relative Absorption Area

above) prevents a fast exponential decay of the ZFC and FC loops with increasing temperature. The ZFC and FC branches obtained under 500 Oe present irreversibility in all the ranges of temperature. However, under an external field of $5 \mathrm{kOe}$, they turn reversible together with the increase in magnetization values since this applied field is strong enough to align most of the magnetic domains. Remarkably, the $\mathrm{M}(\mathrm{T})$ loops do not present any of the following transitions: Verwey at $\sim 124 \mathrm{~K}$, Neel at $\sim 197 \mathrm{~K}$, nor Morin at $\sim 275 \mathrm{~K}$, corresponding to magnetite, wüstite and hematite, respectively, confirming the correct reduction of the iron oxides of the black slags.

Figure 3(b) shows the applied field dependence of the magnetization at 10 and 300 $\mathrm{K}$. In the plots, the paramagnetic contribution of the non-iron impurities is demonstrated by the increase of the magnetization values when decreasing the temperature under high applied fields. Under low applied fields the loops present hysteresis (see inset plot), confirming the ferromagnetic domains mainly caused by $\alpha-\mathrm{Fe}$. The law values of the remanence and coercive fields indicate that the reduced sample is a soft ferromagnetic. These results corroborate the XRD and Mössbauer analysis above.

Following the analysis above, the reduction process of the iron oxide components contained in the black slags is next discussed. As mentioned in the experimental section, the reduction was carried out in an argon atmosphere at high temperatures using graphite as a reducer agent. As the temperature increased in the furnace, a series of chemical reactions occurred that lead to the reduction of the iron contents in the black slag sample. This should have followed a similar three-stage reduction mechanism suggested in the literature $\left(\mathrm{Fe}_{2} \mathrm{O}_{3} \rightarrow \mathrm{Fe}_{3} \mathrm{O}_{4} \rightarrow \mathrm{FeO} \rightarrow \mathrm{Fe}\right)$ [27]. Although there is also the possibility that some of the stages do not occur or they occur simultaneously [28, 29]. In order to elucidate the sequence of the reactions occurring in the process, the Gibbs free energies and enthalpy changes of the reactions were calculated using the Shomate equation provided by the National Institute of Standards and Technology (NIST) [30]. The relationship of both thermodynamic quantities with temperature is shown in Fig. 4 which considers the conditions during the experimental procedure described above. 

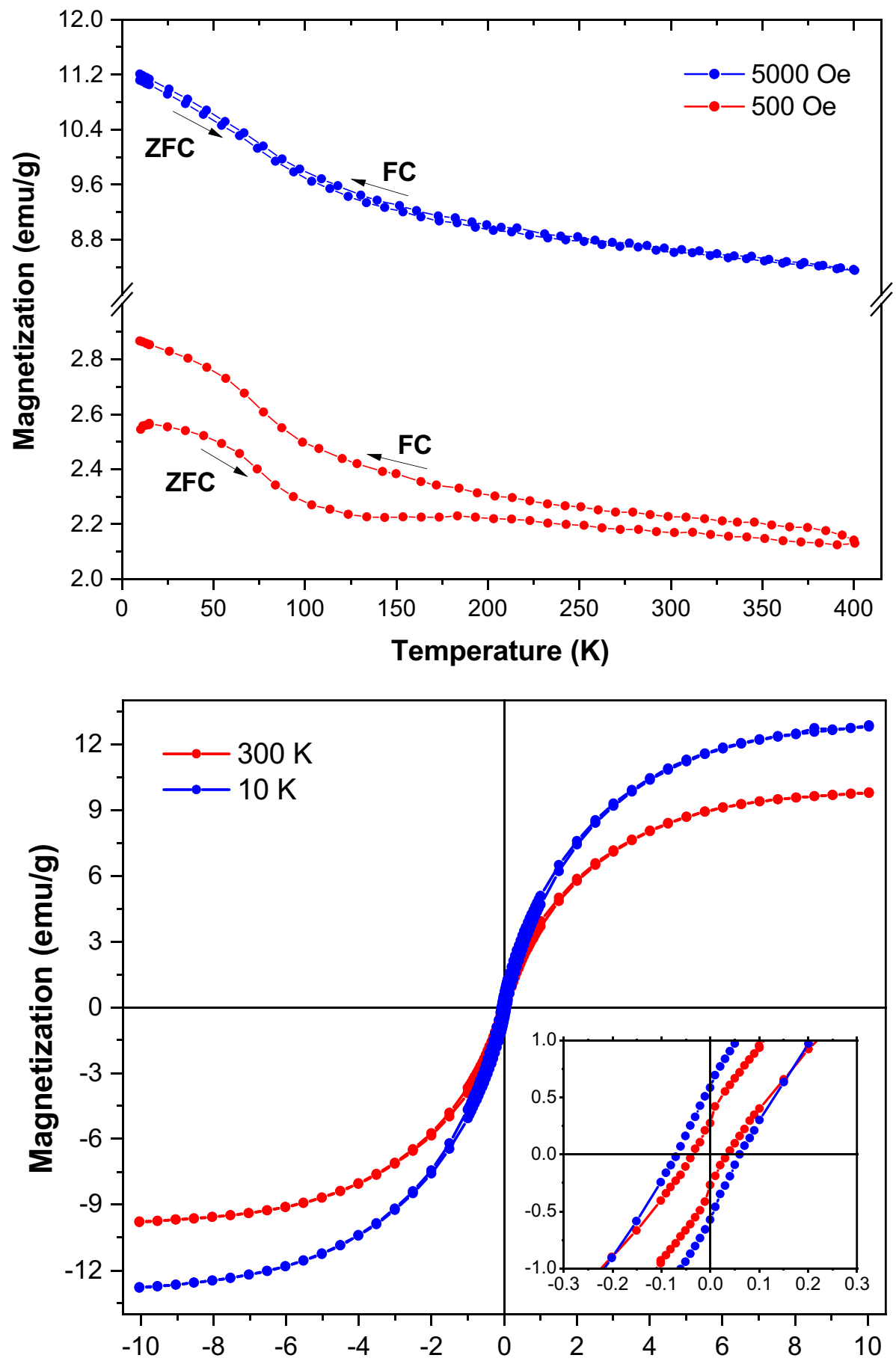

Field (kOe)

Fig. 3 Magnetization vs temperature (a) and magnetization vs magnetic applied field (b) responses of the black slag powder after the carbothermal reduction 
Fig. 4 Gibbs free energy (a) and enthalpy change (b) of the reactions occurred during the carbothermal reduction process of black slags formed in an electrical arc furnace during industrial steelmaking


Since the initial black slag does not contain hematite, the carbothermal process would start with the reduction of the magnetite content by graphite given by the equations

$$
\begin{gathered}
2 \mathrm{Fe}_{3} \mathrm{O}_{4}+\mathrm{C} \rightarrow 6 \mathrm{FeO}+\mathrm{CO}_{2} \\
\mathrm{Fe}_{3} \mathrm{O}_{4}+\mathrm{C} \rightarrow 3 \mathrm{FeO}+\mathrm{CO}
\end{gathered}
$$

the equations (1) and (2) are exergonic at temperatures above $500{ }^{\circ} \mathrm{C}$ (see Fig. 4a). Then, carbon dioxide should have interacted easily with the solid graphite because it is in a gaseous state. This would facilitate the disproportionation of carbon dioxide through the reaction

$$
\mathrm{CO}_{2}+\mathrm{C} \rightarrow 2 \mathrm{CO}
$$

which was performed at $1000^{\circ} \mathrm{C}$ in the present work (the last reaction is only possible at temperatures above $700{ }^{\circ} \mathrm{C}$ as seen in Fig. 4a). Eventually, the reduction of wüstite content in the black slag due to the interaction with graphite follows as

$$
\mathrm{FeO}+\mathrm{C} \rightarrow \mathrm{Fe}+\mathrm{CO}
$$



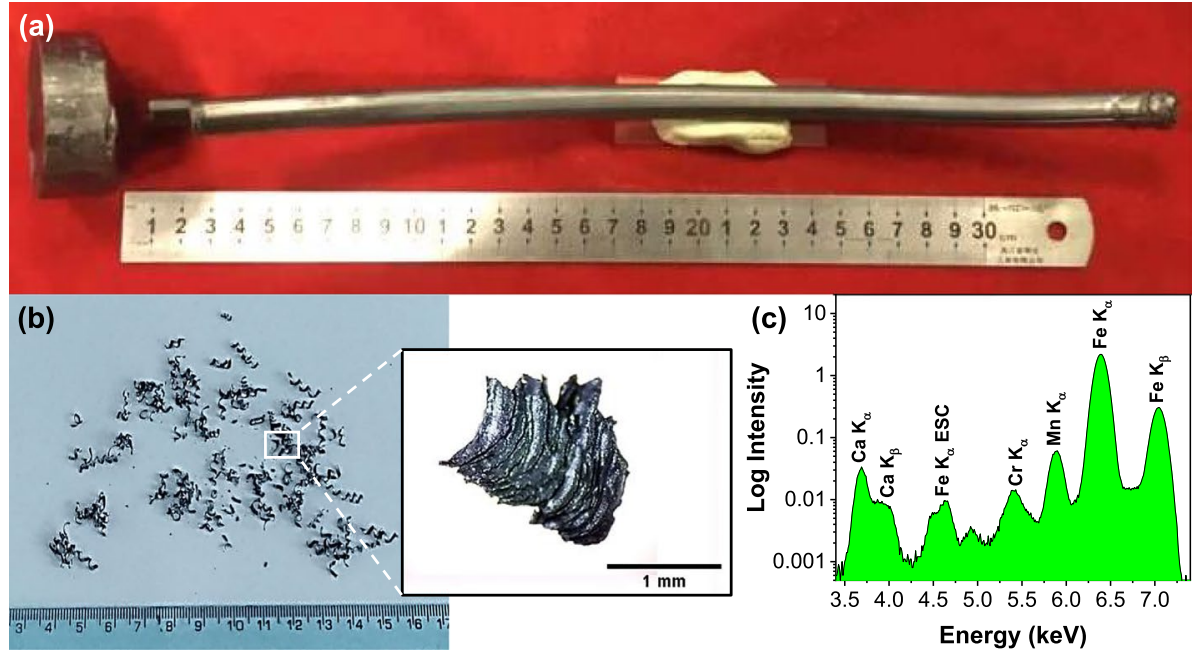

Fig. 5 HRB335 steel rod elaborated from the reduced powder obtained after the carbothermal reduction of the black slag (a), Photography of the recycled HRB335 steel chips and a microscope image taken at 40× magnification (b), XRF spectrum of the HRB335 steel chips (c)

$$
2 \mathrm{FeO}+\mathrm{C} \rightarrow 2 \mathrm{Fe}+\mathrm{CO}_{2}
$$

and thus, the iron is recovered from the black slags. The reactions described in equations (4) and (5) where achieved by setting the temperature to $1200{ }^{\circ} \mathrm{C}$ in the present work (see experimental section) since the spontaneity of the reactions occur at temperatures above 900 ${ }^{\circ} \mathrm{C}$ and $1000{ }^{\circ} \mathrm{C}$, respectively (see Fig 4a) and are expected to occur at higher temperatures than reactions (1), (2) and (3).

On the other hand, it is important to note that all five equations above are endothermic as is observed in Fig. 4b. However, the entropic increase at high temperatures makes them viable. That is the reason why reduction through gaseous interaction with carbon monoxide is not being considered. In this way, the reactions

$$
\begin{gathered}
2 \mathrm{Fe}_{3} \mathrm{O}_{4}+4 \mathrm{CO} \rightarrow 6 \mathrm{Fe}+\mathrm{CO}_{2} \\
\mathrm{FeO}+\mathrm{CO} \rightarrow \mathrm{Fe}+\mathrm{CO}_{2}
\end{gathered}
$$

are discarded even though they are exergonic at high temperatures and would require an increase in the concentration of carbon monoxide relative to that of carbon dioxide to force the reduction $[8,31,32]$. Otherwise, the direction of the reactions (6) and (7) would be in the backward direction i.e., the iron would oxidize, which according to our results above, it did not happen. Moreover, the reaction

Table 2 Elemental chemical composition obtained by XRF of recycled HRB335 chips from black slags

\begin{tabular}{lllll}
\hline Elements & Fe & Ca & Mn & Cr \\
\hline XRF (\%) & 96.41 & 1.70 & 1.67 & 0.22 \\
\hline
\end{tabular}




$$
\mathrm{Fe}_{3} \mathrm{O}_{4}+\mathrm{CO} \rightarrow 3 \mathrm{FeO}+\mathrm{CO}_{2}
$$

is also discarded even though it is exergonic. Note that this equation implies the previous formation of carbon monoxide which at the reported temperatures, it is not sufficient enough to reduce magnetite to wüstite. Thus equations (1) and (2) are most probable.

The reduced black slags were recycled into a HRB335 steel ingot by the following consolidation at $400^{\circ}$ C. Fig. 5(a) shows the HRB335 steel piece where a compact of $5.8 \mathrm{~cm}$ diameter and $3 \mathrm{~cm}$ thickness remains after the extrusion process leading to a rod of $30 \mathrm{~cm}$ length and $19 \mathrm{~mm}$ diameter. The rod has a smooth surface and is bent due to contraction during cooling in response to the thermal dilatation during the hot extrusion process. The rod was filled and Figure 5(b) shows the chips. They are metal in colour, curled in shape and of different sizes. Also, the surface of the chips is rough, have many small cracks and their borders are not uniform due to micro-vibrations during cutting by the WEDM. Fig. 5(c) shows the XRF spectrum of the chips. The detected elements are listed in Table 2. The results indicate the presence of $\mathrm{Fe}(96.41 \%)$ as the major component and $\mathrm{Ca}$ $(1.70 \%), \mathrm{Mn}(1.67 \%)$ and $\mathrm{Cr}(0.22 \%)$ in less proportion. The role of manganese is to improve the hardness, whereas chromium increases the resistance to corrosion and oxidation [33].

\section{Conclusions}

A black slag sample was collected from the electrical arc furnace from the SIDERPERU steel plant and reduced through a carbothermal reaction. The XRD analysis shows that the black slag contains calcium silicates and iron oxides such as $\mathrm{CaSi}, \mathrm{Ca}_{2} \mathrm{SiO}_{4}, \mathrm{Ca}_{2} \mathrm{Fe}_{2} \mathrm{O}_{5}, \mathrm{Fe}_{3} \mathrm{O}_{4}$, and $\mathrm{FeO}$. After the carbothermal reduction, $\alpha-\mathrm{Fe}$ and $\gamma$-Fe are achieved, as expected. Moreover, some other components such as $\mathrm{Ca}_{2} \mathrm{SiO}_{4}$ and $\mathrm{Ca}_{2} \mathrm{Fe}_{2} \mathrm{O}_{5}$ partially reduced to $\mathrm{SiO}_{2}$ and $\mathrm{CaO}$. However, some CaSi and $\mathrm{Ca}_{2} \mathrm{SiO}_{4}$ remain. The MS of the sample before the reduction process indicate that wüstite is nonstoichiometric and confirm the presence of $\mathrm{Ca}_{2} \mathrm{Fe}_{2} \mathrm{O}_{5}$ and $\mathrm{Fe}_{3} \mathrm{O}_{4}$. After the reduction process, a hyperfine field distribution related to $\alpha-\mathrm{Fe}$ and one singlet of $\gamma$-Fe are observed. The paramagnetic doublet detected is associated with the tetrahedral $\mathrm{Fe}^{3+}$ site. Additionally, another sextet is found but not identified with some phase related to the carbothermal reduction. The magnetic measurements show a ferromagnetic behaviour that should correspond to $\alpha-\mathrm{Fe}$ and without the evidence of remaining iron oxides. The thermodynamic analysis and the characteristics of our procedure suggest a two-stage reduction process $\left(\mathrm{Fe}_{3} \mathrm{O}_{4} \rightarrow \mathrm{FeO} \rightarrow \mathrm{Fe}\right)$, releasing significant amounts of carbon monoxide and dioxide during the process. Therefore, the iron oxides contained in the black slag can be successfully reduced to $\alpha$-Fe. The black slags were successfully recycled to HRB335 steel.

Acknowledgements This work was supported by the CONCYTEC - World Bank - FONDECYT program "Incorporación de Investigadores", Contract No. 12 -2019 - FONDECYT - BM - INC. INV. The authors are indebted to Mr E. Hurtado Aguilar and Mr R.H Cervantes Altuna for allowing us access to SIDERPERU to collect the samples.

Open Access This article is licensed under a Creative Commons Attribution 4.0 International License, which permits use, sharing, adaptation, distribution and reproduction in any medium or format, as long as you give appropriate credit to the original author(s) and the source, provide a link to the Creative Commons licence, and indicate if changes were made. The images or other third party material in this article are included in the article's Creative Commons licence, unless indicated otherwise in a credit line to the material. If material is not included in the article's Creative Commons licence and your intended use is not permitted by statutory regulation or exceeds the permitted use, you will need to obtain permission directly from the copyright holder. To view a copy of this licence, visit http://creativecommons.org/licenses/by/4.0/. 


\section{References}

1. Nakhaei, F., Irannajad, M.: Reagents types in flotation of iron oxide minerals: A review. Miner. Process. Extr. Metall. Rev. 39, 89-124 (2018). https://doi.org/10.1080/08827508.2017.1391245

2. Gonzalez, I.H., Kamiński, J.: The iron and steel industry: a global market perspective. Gospod. Surowcami Miner. Resour. Manag. 5-28, (2011)

3. Nechifor, V., Calzadilla, A., Bleischwitz, R., Winning, M., Tian, X., Usubiaga, A.: Steel in a circular economy: Global implications of a green shift in China. World Dev. 127, 104775 (2020). https://doi.org/ 10.1016/j.worlddev.2019.104775

4. Liu, Y., Li, H., Huang, S., An, H., Santagata, R., Ulgiati, S.: Environmental and economic-related impact assessment of iron and steel production. A call for shared responsibility in global trade. J. Clean. Prod. 269, 122239 (2020). https://doi.org/10.1016/j.jclepro.2020.122239

5. Guo, J., Bao, Y., Wang, M.: Steel slag in China: Treatment, recycling, and management. Waste Manag. 78, 318-330 (2018). https://doi.org/10.1016/j.wasman.2018.04.045

6. Mos, Y.M., Vermeulen, A.C., Buisman, C.J.N., Weijma, J.: X-Ray Diffraction of Iron Containing Samples: The Importance of a Suitable Configuration. Geomicrobiol. J. 35, 511-517 (2018). https://doi.org/ 10.1080/01490451.2017.1401183

7. Heikkilä, A., Iljana, M., Bartusch, H., Fabritius, T.: Reduction of Iron Ore Pellets, Sinter, and Lump Ore under Simulated Blast Furnace Conditions. steel Res. Int. 91, 2000047 (2020). https://doi.org/10.1002/ srin.202000047

8. Treptow, R.S., Jean, L.: The iron blast furnace: A study in chemical thermodynamics. J. Chem. Educ. 75, 43-47 (1998). https://doi.org/10.1021/ed075p43

9. Chen, Y., Zuo, H.: Review of hydrogen-rich ironmaking technology in blast furnace. Ironmak. Steelmak. 48, 749-768 (2021). https://doi.org/10.1080/03019233.2021.1909992

10. Sunil, S.R., Rayapudi, V., Dhawan, N.: Recovery of Iron Values from Discarded Iron Ore Slimes. Mining, Metall. Explor. 37, 287-295 (2020). https://doi.org/10.1007/s42461-019-00119-2

11. Sarfo, P., Wyss, G., Ma, G., Das, A., Young, C.: Carbothermal reduction of copper smelter slag for recycling into pig iron and glass. Miner. Eng. 107, 8-19 (2017). https://doi.org/10.1016/j.mineng.2017.02. 006

12. Lyu, Q., Qie, Y., Liu, X., Lan, C., Li, J., Liu, S.: Effect of hydrogen addition on reduction behavior of iron oxides in gas-injection blast furnace. Thermochim. Acta. 648, 79-90 (2017). https://doi.org/10. 1016/j.tca.2016.12.009

13. Ter Teo, P., Zakaria, S.K., Salleh, S.Z., Taib, M.A.A., Mohd Sharif, N., Abu Seman, A., Mohamed, J.J., Yusoff, M., Yusoff, A.H., Mohamad, M., Masri, M.N., Mamat, S.: Assessment of Electric Arc Furnace (EAF) Steel Slag Waste's Recycling Options into Value Added Green Products. A Review. Metals (Basel). 10, 1347 (2020). https://doi.org/10.3390/met10101347

14. Menad, N.-E., Kana, N., Seron, A., Kanari, N.: New EAF Slag Characterization Methodology for Strategic Metal Recovery. Materials (Basel). 14, 1513 (2021). https://doi.org/10.3390/ma14061513

15. Gheisari, M., Mozafari, M., Niyaifar, M., Amighian, J., Soleimani, R.: Observation of Small Exchange Bias in Defect Wüstite (Fe0.93O). Nanoparticles. J. Supercond. Nov. Magn. 26, 237-242 (2013). https:// doi.org/10.1007/s10948-012-1821-9

16. Elias, D.J., Linnett, J.W.: Oxidation of metals and alloys. Part 3.-Mössbauer spectrum and structure of wustite. Trans. Faraday Soc. 65, 2673-2677 (1969). https://doi.org/10.1039/TF9696502673

17. Dyar, M.D., Sklute, E.C.: Mossbauer spectroscopy: Theory and laboratory spectra of geologic materials. Remote Compos. Anal. Tech. Underst. Spectrosc. Mineral. Geochemistry Planet. Surfaces. 147-167, (2019)

18. Kuzmann, E., Eissa, N., Molnár, B., Vértes, A.: Mössbauer study of iron reduction in hematite containing mineral originated from Aswan area in Egypt. J. Radioanal. Nucl. Chem. Lett. 127, 169-176 (1988). https://doi.org/10.1007/BF02164862

19. Vandenberghe, R.E., De Grave, E.: Application of Mössbauer Spectroscopy in Earth Sciences. In: Mössbauer Spectroscopy, pp. 91-185. Springer, Berlin Heidelberg, Berlin, Heidelberg (2013)

20. Hirabayashi, D., Yoshikawa, T., Mochizuki, K., Suzuki, K., Sakai, Y.: Formation of brownmillerite type calcium ferrite (Ca2Fe2O5) and catalytic properties in propylene combustion. Catal. Lett. 20061101. 110, 155-160 (2006). doi: 10.1007/S10562-006-0104-0

21. Yamauchi, S., Kurimoto, Y., Sakai, Y.: Mössbauer Spectroscopic Characterization of Iron in Ashes Made from the Ancient Woods Excavated in the Foothills of Mt. Chokai. J. Nucl. Radiochem. Sci. 17, 1-7 (2017). https://doi.org/10.14494/jnrs.17.1

22. Zhong, L., Frandsen, C., Mørup, S., Hu, Y., Pan, C., Cleemann, L.N., Jensen, J.O., Li, Q.: 57Fe-Mössbauer spectroscopy and electrochemical activities of graphitic layer encapsulated iron electrocatalysts 
for the oxygen reduction reaction. Appl. Catal. B Environ. 221, 406-412 (2018). https://doi.org/10. 1016/j.apcatb.2017.09.014

23. Yamagishi, T., Yamauchi, S., Suzuki, K., Suzuki, T., Kurimoto, Y., Takayama, T., Sakai, Y.: Mössbauer and Raman spectroscopic characterization of iron and carbon in iron-loaded Japanese cypress charcoal. J. Wood Sci. 66, 82 (2020). https://doi.org/10.1186/s10086-020-01930-y

24. Dyar, M.D., Agresti, D.G., Schaefer, M.W., Grant, C.A., Sklute, E.C.: Mössbauer spectroscopy of earth and planetary materials. Annu. Rev. Earth Planet. Sci. 34, 83-125 (2006). https://doi.org/10.1146/annurev.earth. 34.031405.125049

25. Cook, P., Cashion, J.: Mössbauer study of iron catalysis in Victorian brown coal liquefaction. Fuel. 66, 669677 (1987). https://doi.org/10.1016/0016-2361(87)90277-8

26. Silva, V.A.J., Andrade, P.L., Silva, M.P.C., Bustamante, D.A., De Los Santos Valladares, L., Albino Aguiar, J.: Synthesis and characterization of Fe3O4 nanoparticles coated with fucan polysaccharides. J. Magn. Magn. Mater. 343, 138-143 (2013). https://doi.org/10.1016/j.jmmm.2013.04.062

27. Mousa, E.A., Bahgat, M., El-Geassy, A.A.: Reduction of iron oxide compacts with simulated blast furnace top and shaft gases to mitigate CO 2 emissions. Ironmak. Steelmak. 40, 452-459 (2013). https://doi.org/10. 1179/1743281212Y.0000000075

28. Wimmers, O.J., Arnoldy, P., Moulijn, J.A.: Determination of the reduction mechanism by temperatureprogrammed reduction: application to small iron oxide (Fe2O3) particles. J. Phys. Chem. 90, 1331-1337 (1986). https://doi.org/10.1021/j100398a025

29. Chen, Z., Dang, J., Hu, X., Yan, H.: Reduction kinetics of hematite powder in hydrogen atmosphere at moderate temperatures. Metals (Basel). 8, (2018). https://doi.org/10.3390/met8100751

30. Chase, M.: NIST-JANAF Thermochemical Tables, 4th Edition, (1998)

31. Ubando, A.T., Chen, W.-H., Ong, H.C.: Iron oxide reduction by graphite and torrefied biomass analyzed by TG-FTIR for mitigating CO2 emissions. Energy. 180, 968-977 (2019). https://doi.org/10.1016/j.energy. 2019.05.149

32. Sheshukov, O., Mikheenkov, M., Vedmid, L., Nekrasov, I., Egiazaryan, D.: Mechanism of Ion-Diffusion Solid-Phase Reduction of Iron Oxides of Technogenic Origin in the Presence of the Liquid Phase and without it. Metals (Basel). 10, 1564 (2020). https://doi.org/10.3390/met10121564

33. Lavakumar, A.: Concepts in Physical Metallurgy Concise lecture notes. IOP Publishing (2017)

Publisher's note Springer Nature remains neutral with regard to jurisdictional claims in published maps and institutional affiliations.

\section{Authors and Affiliations}

\section{H. A. Cabrera-Tinoco ${ }^{1,2} \cdot$ R. A. Valencia-Bedregal ${ }^{1}$ - L. E. Borja-Castro ${ }^{1}$. M. I. Valerio-Cuadros ${ }^{1,3} \cdot$ A. G. Bustamante Dominguez ${ }^{1} \cdot$ Xiaoli Zhao $^{4}$. Youyun Zhang ${ }^{4} \cdot$ Chengmu Zheng $^{4} \cdot$ N. O. Moreno ${ }^{5}$. Deliang Zhang ${ }^{4}$. C. H. W. Barnes ${ }^{6}$ L. De Los Santos Valladares ${ }^{1,4,6}$}

1 Laboratorio de Cerámicos y Nanomateriales, Facultad de Ciencias Físicas, Universidad Nacional Mayor de San Marcos, Ap. Postal 14-0149, Lima, Perú

2 Facultad de Ingeniería, Universidad Continental, Lima 15311, Perú

3 Departamento de Física, Universidade Estadual de Maringá, Av. Colombo, 5790 - Jardim Universitário, Maringá, PR 87020-900, Brazil

4 School of Materials Science and Engineering, Northeastern University, No 11, Lane 3, Wenhua Road, Heping District, Shenyang 110819, Liaoning, People's Republic of China

5 Departamento de Física, Universidade Federal de Sergipe, São Cristóvão, SE 49100-000, Brazil

6 Cavendish Laboratory, Department of Physics, University of Cambridge, J.J Thomson Ave, Cambridge CB3 OHE, UK 